\title{
Attentional bias and its temporal dynamics among war veterans suffering from chronic pain: investigating the contribution of post-traumatic stress symptoms
}

Mahdi Mazidi ${ }^{\mathbf{a}, \mathbf{b}}$, Kelsey Vig ${ }^{\mathbf{c}}$, Seyran Ranjbar ${ }^{\mathbf{d}}$,Mohammad-Reza Ebrahimi ${ }^{\mathbf{e}}$, Ali Khatibi ${ }^{\mathbf{f}}$

a Centre for the Advancement of Research on Emotion, The University of Western Australia, Crawley, WA, Australia

b Department of Clinical Psychology, University of Social Welfare and Rehabilitation Sciences, Tehran, Iran

${ }^{\mathbf{c}}$ Department of Psychology, University of Regina, Regina, SK, Canada

${ }^{\text {d }}$ Psychology Department, Shahid Beheshti University, Tehran, Iran

e Military Psychiatry Center, 505 Psychiatric hospital, AJA University of Medical Sciences, Tehran, Iran

f Department of Neurology and Neurosurgery, McGill University, Montreal, QC, Canada

* Corresponding Author: Ali Khatibi, ali.khatibi@gmail.com, address: NW141, Montreal Neurological Institute, Montreal, Canada, Phone: +1-514-398-5564

Funding sources: This research did not receive any specific grant from funding agencies in the public, commercial, or not-for-profit sectors.

Conflict of interests: Authors declare no conflict of interest regarding the current submission 


\begin{abstract}
Background: Cognitive models propose that attentional dysregulation, including an attentional bias towards threat, is one of the factors through which chronic pain and posttraumatic stress symptoms (PTSS) maintain and exacerbate one another. The current investigation assessed the attentional bias for painful facial expressions and its relationship with PTSS, using both traditional and variability-based attentional bias measures, among veterans with chronic pain and PTSS and controls.
\end{abstract}

Method: Fifty-four veterans with chronic pain and 30 age/education-matched controls participated in this investigation. Participants completed a self-report measure of PTSS and a modified version of the dot-probe task with painful, happy, and neutral facial expressions. Attention was assessed using both traditional and variability-based reaction time measures of attentional bias.

Results: Veterans directed attention away from painful facial expressions (i.e., avoidance) relative to both the control group (between-subject effect) and relative to neutral faces (withinsubject effect). Veterans also showed significantly elevated attentional bias variability for both happy and painful facial expressions compared to controls. Attentional bias variability for happy and painful facial expressions was correlated with PTSS among all participants.

Conclusion: Veterans with chronic pain and PTSS avoided pain-related stimuli and displayed an overall attentional dysregulation for emotional facial expressions. Avoidance of pain cues may be a coping strategy that these individuals develop under stressful conditions. Implications, limitations, and directions for future research are discussed.

Keywords: Attentional bias; trial-level bias score; post-traumatic stress disorder; chronic pain; veterans; dot-probe task 


\section{Introduction}

Various theoretical models include attentional biases (ABs), or the preferential allocation of attention towards or away from certain types of stimuli (Cisler \& Koster, 2010), as important mechanisms influencing the development and maintenance of psychological disorders (Beck \& Clark, 1997; Mathews \& Mackintosh, 1998). ABs include hypervigilance, where attention is directed towards relevant stimuli, maintenance, where there is difficulty disengaging attention from relevant stimuli, and avoidance, where attention is directed away from relevant stimuli (Bar-Haim, Lamy, Pergamin, Bakermans-Kranenburg, \& van IJzendoorn, 2007). Most of the research on AB and psychological disorders has examined an $\mathrm{AB}$ for threat in anxiety-related disorders, including post-traumatic stress disorder (PTSD). Some researchers describe the association between $\mathrm{AB}$ for threat and post-traumatic stress symptoms (PTSS) as a robust phenomenon (Buckley, Galovski, Blanchard, \& Hickling, 2003; Constans, 2005) while others suggest that results supporting this association are mixed and weak at best (Schäfer, Zvielli, Hofler, Wittchen, \& Bernstein, 2018). Several studies with null findings have been reported in the literature on the AB for threat and PTSS (e.g., Elsesser, Sartory, \& Tackenberg, 2004, 2005), and failure to replicate significant findings is common in the AB literature (e.g., Kimble, Frueh, \& Marks, 2009).

Chronic pain has been described as pain that persists for at least 3 months and leads to functional impairment (International Association of the Study of Pain, 1986). Researchers and clinicians have largely shifted away from a purely biomedical understanding of chronic pain and moved towards a biopsychosocial perspective, including a focus on how cognition contributes to chronic pain. For example, the fear-avoidance model recognizes the important role of attentional processes in the maintenance of chronic pain (Crombez, Eccleston, Van Damme, Vlaeyen, \& Karoly, 2012). When pain is acute, hypervigilance for pain information can be adaptive in the short-term and help the physical recovery process by encouraging 
avoidance of behaviors that may cause further injury; but, hypervigilance and behavioral avoidance after the acute pain stage can lead to disuse of muscle and a lower pain threshold (Crombez et al., 2012). Despite theoretical support for chronic pain-related ABs, empirical support for these biases has been inconsistent. According to Crombez and colleagues (2013), there is a small $(d=0.134)$, but significant, within-group AB towards sensory pain words in individuals with chronic pain. Healthy controls did not demonstrate the same AB; however, there was no significant difference in the AB for pain-related stimuli between individuals with chronic pain and healthy controls.

Chronic pain frequently co-occurs with anxiety disorders, and with PTSS in particular. An estimated $18.9 \%$ of individuals with chronic pain reported trauma exposure and PTSS (Ravn, Vaegter, Cardel, \& Andersen, 2018). Prevalence estimates are even greater when examining specific populations. For example, recent reviews found that $50 \%$ of veterans with chronic pain also had PTSS (Fishbain, Pulikal, Lewis, \& Gao, 2017; Siqveland, Hussain, Lindstrom, Ruud, \& Hauff, 2017). Various theoretical models posit potential explanations for the association between chronic pain and PTSS/PTSD. The mutual maintenance model put forth by Sharp and Harvey (2001) suggests that chronic pain and PTSD maintain and exacerbate one another through specific cognitive, affective, and behavioral components (e.g., avoidance, attentional and reasoning biases). The shared vulnerability model proposed by Asmundson and colleagues (Asmundson, Coons, Taylor, \& Katz, 2002; Asmundson \& Katz, 2009) also includes ABs as one of the potential mechanisms that contribute to the co-occurrence of chronic pain and PTSD. However, once again, theoretical support exceeds empirical support as there is very little research examining ABs in individuals with comorbid chronic pain and PTSD.

ABs towards pain-related stimuli have been demonstrated in individuals with chronic pain (e.g., Khatibi, Dehghani, Sharpe, Asmundson, \& Pouretemad, 2009; Mahmoodi- 
Aghdam, Dehghani, Ahmadi, Khorrami Banaraki, \& Khatibi, 2017) and those with PTSS separately (e.g., Thomas, Goegan, Newman, Arndt, \& Sears, 2013); however, to date, only two studies have investigated ABs in participants with comorbid chronic pain and PTSS. Researchers used the modified Stroop task, a variation of the original Stroop task (Stroop, 1935), with lists of emotionally salient (i.e., pain-related, trauma-related, and positive) and neutral words printed in various colors (Beck, Freeman, Shipherd, Hamblen, \& Lackner, 2001). Participants were instructed to name the color of each word (e.g., "agony" written in blue). Longer RTs when reading emotionally salient words compared to neutral words indicates the presence of an AB (Bar-Haim et al., 2007). The modified Stroop task only provides an overall index of $\mathrm{AB}$; that is, the paradigm cannot be used to assess the direction of an $\mathrm{AB}$ (i.e., hypervigilance, maintenance, or avoidance). The researchers compared biases across participants with comorbid chronic pain and PTSD, those with chronic pain only, and trauma-exposed controls (Beck et al., 2001). Individuals with comorbid chronic pain and PTSD and those with chronic pain only displayed an AB for pain-related words, as evidenced by both within- and between-group effects. In other words, individuals with chronic pain (with or without comorbid PTSD) responded slower to pain-related words compared to neutral or positive words, and they responded slower to pain-related words compared to trauma-exposed controls.

More recently, researchers used the startle probe paradigm in combination with painrelated, trauma-related, health-related, pleasant, and neutral words to compare $\mathrm{ABs}$ in individuals with chronic pain alone, PTSD alone, comorbid chronic pain and PTSD, any other anxiety disorder, and trauma-exposed controls (Carleton, Duranceau, McMillan, \& Asmundson, 2018). The researchers hypothesized that participants would display AB towards diagnosis-congruent stimuli (e.g., pain-related stimuli for participants with chronic pain), which were thought to be perceived as the most threatening. However, compared to participants 
with anxiety disorders and the control group, individuals with PTSD or chronic pain showed greater startle intensity and delayed startle peak (responded more slowly, indicating higher fear-related reactivity) for all words, regardless of their types. The authors concluded that their results suggest psychophysiologically measurable differences that accompany chronic pain and PTSD, which could be indicative of an AB that is not specific to disorder-relevant stimuli.

The two studies described above provide somewhat inconsistent results for $\mathrm{AB}$ in individuals with chronic pain and PTSS. Due to methodological limitations, it is difficult to confidently draw conclusions about ABs in co-occurring chronic pain and PTSS from these studies. First, pictorial stimuli are more ecologically valid than word stimuli (Dear, Sharpe, Nicholas, \& Refshauge, 2011a); but, both investigations discussed above used word stimuli. Second, concerns have been raised in the literature regarding how results from the modified Stroop task are interpreted and the potential mechanisms underlying longer RTs (e.g., Algom, Chajut, \& Lev, 2004). Results from the modified Stroop task also do not provide information on whether an $\mathrm{AB}$ is characterized by hypervigilance, maintenance, or avoidance. A different measure of $\mathrm{AB}$, the pictorial dot-probe task, may provide a more valid assessment of $\mathrm{AB}$ for individuals with chronic pain and PTSS. Another strength of the dot-probe task is that it allows researchers to calculate variability-based measures of AB, such as Trial-Level Bias Scores (TL$\mathrm{BSs}$ ) and the attentional bias variability (ABV) index, which account for intra-individual fluctuations of attention toward and away from stimuli over time (Iacoviello et al., 2014; Zvielli, Bernstein, \& Koster, 2015). Elevated ABV has been associated with higher levels of emotion dysregulation (Bardeen, Daniel, Hinnant, \& Orcutt, 2017) and impaired cognitive control (Swick \& Ashley, 2017). Some researchers have employed TL-BSs and observed positive associations between within-subject variability in ABs and PTSS (Yuval, Zvielli, \& Bernstein, 2016). To the best of our knowledge, no investigation to date has used variabilitybased measures when examining individuals with chronic pain and PTSS. 
The current investigation examined ABs for pain-related stimuli in individuals with chronic pain and PTSS. Focusing on the severity of PTSS, as opposed to PTSD as a diagnosis, may be more informative given that subsyndromal levels of PTSD are also associated with significant impairments (Bryant et al., 2015; Ravn et al., 2018; Stein, Walker, Hazen, \& Forde, 1997). We hypothesized that compared to controls, veterans with chronic pain and PTSS would demonstrate an AB towards painful facial expressions. Consistent with past research (Carlson, Aday, \& Rubin, 2018), we also hypothesized that veterans with chronic pain and PTSS would display greater temporal variability in the AB for both types of emotional stimuli, irrespective of valence. Finally, we expected the temporal dynamics of AB to be associated with PTSS.

\section{Method}

\subsection{Participants}

Veterans referred to a medical council between April 2015 to March 2016 for chronic pain (i.e., persistent pain for at least 3 months) were approached by the experimenter (M.M.) while waiting for their medical visits and invited to participate in the research. All veterans had long-term injuries (not including traumatic brain injuries) due to war participation. Age and education cohort-matched control participants without any history of military service were recruited from the general population to serve as the control group. Individuals were eligible to participate in the investigation if they were between 18 and 65 years old, had normal or corrected to normal vision, were able to use both hands, and could understand and speak Persian fluently. Exclusion criteria included any diagnosis of a neurological disorder, a history of psychotic disorder, or current substance abuse. The investigation was approved by the research ethics committee at AJA medical university. All participants provided written informed consent prior to participation. 
Sixty-five male veterans with chronic pain and 30 controls agreed to participate in the investigation. Data from 11 veterans were excluded from analysis; two were removed due to technical problems, five returned questionnaires incomplete, and four were removed due to poor performance in the dot-probe task (i.e., more than $20 \%$ skipped trials or incorrect responses). This cut-off for poor performance has been used in past $\mathrm{AB}$ research (Fani et al., 2012; Fani, Bradley-Davino, Ressler, \& McClure-Tone, 2011). The final sample included 54 veterans $($ mean age $=51.44$ years, $\mathrm{SD}=3.78$, range $=43-60$ years; $100 \%$ married; mean education $=12.06$ years, $\mathrm{SD}=3.84$, range $=5-22$ years) and 30 controls (mean age $=49.17$ years, $\mathrm{SD}=6.60 ;$ range $=36-59$ years $; 93.3 \%$ married , mean education $=13.33$ years, $\mathrm{SD}=$ 3.62 , range $=5-22$ years). The average pain duration among veteran participants was 24.81 years $(\mathrm{SD}=9.32)$, and the distribution of pain locations was as follows: $10.33 \%$ upper limbs, $10.34 \%$ lower limbs, $5.16 \%$ back pain, and $74.13 \%$ pain in more than one location. The majority of the veterans attributed their chronic pain to an injury sustained during a traumatic experience $(81.13 \%)$.

\subsection{Materials and procedure}

2.2.1. Mississippi Scale for Combat-Related PTSD (M-PTSD; Keane, Caddell, \& Taylor, 1988)

The M-PTSD is a 35-item self-report scale that produces a total score indicative of PTSD symptom severity. Both military and civilian versions of this scale have shown good psychometric properties, with a test-retest reliability of .97 (Keane et al., 1988), and internal consistency of .96 for help-seeking (McFall Miles, Smith Dale, Mackay Priscilla, \& Tarver David, 1990) and .93 for community-based veterans, respectively (Kulka et al., 1990). This scale has been validated in Iran in a comparable sample of individuals and showed good to excellent psychometric properties (Goodarzi, 2003). Original and civilian versions of the M- 
PTSD were used to assess PTSS in veterans and healthy controls, respectively. In the current investigation, internal consistency (Cronbach's alpha) of the M-PTSD was .91.

\subsubsection{Visual analogue scale (VAS)}

The pain VAS was used to assess past, present, and anticipated future pain severity. A VAS is a 10-cm ungraded horizontal line with one anchor at either end. The left anchor indicates "no pain at all" and the right anchor indicates "maximum possible pain". Participants were asked to use three VAS lines to rate their average pain intensity in the previous week, current pain, and expected pain in the next week. VAS has shown adequate test-retest reliability among literate chronic pain patients ( $r=0.94$; Ferraz et al., 1990). It also has been shown to be highly correlated with other measures of pain (Hawker, Mian, Kendzerska, \& French, 2011). Given our clinical sample, we chose VAS because of its simple administration and understandability.

\subsubsection{Fear of Pain Questionnaire (FPQ-III; McNeil \& Rainwater, 1998)}

The FPQ-III is a 30-item self-report questionnaire designed to evaluate fear of various painful experiences (e.g., "Biting your tongue while eating”). Participants rate items on a 5point Likert scale from 1 (not at all) to 5 (extreme). The FPQ-III has high test-retest reliability $(r=0.92)$, and internal consistency (Cronbach's alpha $=0.74$; McNeil \& Rainwater, 1998) and has been used in both clinical and non-clinical populations (Roelofs, Peters, Fassaert, \& Vlaeyen, 2005). The Persian version of the questionnaire has reported good psychometric properties in previous research (Dehghani, Mohammadi, Sharpe, \& Khatibi, 2018). In the current investigation, the internal consistency for the FRQ-III was .92. Fear of pain was assessed due to its theoretical relevance to chronic pain (Leeuw et al., 2007).

\subsubsection{Depression Anxiety Stress Scales (DASS-42; Lovibond \& Lovibond, 1995)}

The DASS-42 includes three 14-item sections designed to assess depression, anxiety, and stress in the past week. Participants rate items on a 4-point Likert scale from 0 (did not 
apply to me at all) to 3 (applied to me very much, or most of the time). Given our chronic pain sample, the DASS-42 was chosen because it focuses less on somatic symptoms compared to other measures of depression and anxiety (Wood, Nicholas, Blyth, Asghari, \& Gibson, 2010). The DASS-42 has strong construct validity and reliability (Antony, Bieling, Cox, Enns, \& Swinson, 1998) and has been used in previous studies with chronic pain patients (Dehghani, Sharpe, \& Nicholas, 2004). For the current sample, internal consistency for the depression, anxiety, and stress subscales were $.95, .91$, and .93 , respectively.

\subsubsection{Dot-probe task (MacLeod, Mathews, \& Tata, 1986)}

The pictorial version of the dot-probe task used in this investigation was programmed using the Affect 4 software package (Spruyt, Clarysse, Vansteenwegen, Baeyens, \& Hermans, 2010) and presented on a 14-inch monitor ASUS X44H Intel Pentium computer. Each trial began with the presentation of a fixation cross in the center of the monitor. After $500 \mathrm{~ms}$, two pictures of facial expressions were presented one above the other. Each trial consisted of one painful or happy (i.e., target) face and one neutral face from the same person. Faces remained on screen for $500 \mathrm{~ms}$. After the pictures disappeared, a probe (i.e., a dot) appeared in the location of either the neutral or target face. Participants were instructed to respond as quickly and accurately as possible by pressing the down-arrow key if the probe replaced the bottom face or the up-arrow key if the probe replaced the top face. The trial ended automatically after $2000 \mathrm{~ms}$ or immediately after the participant pressed one of the response keys. Inter-trial durations ranged from 800-1000 ms.

The dot-probe task included 16 practice trials, which used nature pictures, and 80 experimental trials. Experimental trials included pairs of painful-neutral and happy-neutral faces set against a grey background. Stimuli consisted of photos of 10 adults ( 5 females) that were taken from the Montreal Database of Facial Expressions (Roy et al., 2007). Non-facial features were removed to avoid distracting participants from processing the facial expressions 
(Nusseck, Cunningham, Wallraven, \& Bulthoff, 2008). Each target face was randomly presented four times in all possible combinations (i.e., target up/dot down; target up/dot up; target down/ dot down and target down/dot up). This version of the dot-probe task has been used in previous studies investigating AB for pain-related information (Mohammadi, Dehghani, Khatibi, Sanderman, \& Hagedoorn, 2015). The dot-probe task took 6 minutes to finish on average and was completed before the questionnaires.

\subsection{Data preparation}

Incorrect responses in the dot-probe task were removed (1.9\% of trials for veterans and $1.1 \%$ of trials for the control group). There was no significant difference between groups for the number of incorrect responses $[t(78.87)=1.57, p=.119]$. In line with the recommendations provided by Price et al. (2015) to enhance reliability and minimize missing values with dotprobe data, outliers in the dot-probe task were Winsorized, a data-driven method that involves reassigning outliers to the nearest value in the valid (i.e., non-outlier) distribution. Winsorizing is a modern and robust method for working with outliers that is supported by statisticians (Erceg-Hurn \& Mirosevich, 2008). It allows researchers to eliminate extreme values while maximizing power and accuracy because more data points are retained for analysis. Using the values recommended by Price et al., (2015), RTs outside 1.5 interquartile ranges from the $25^{\text {th }}$ and $75^{\text {th }}$ percentiles of each participant's RT distribution were rescaled to the closest nonoutlier value.

We calculated traditional indices of AB, as well as TL-BS parameters as measures of the temporal dynamics of $\mathrm{AB}$ (Zvielli et al., 2015). Mean AB was calculated by subtracting the mean reaction time of congruent trials (trials where the probe is presented in the same location as the target face) from the mean reaction time of incongruent trials (trials where the probe is presented in the same location as the neutral face). A positive AB value reflects an $\mathrm{AB}$ towards the target facial expressions while a negative $\mathrm{AB}$ value signifies avoidance or an 
AB away from the target facial expressions. Separate AB indices were calculated for trials with happy faces and those with painful faces.

TL-BSs were computed by subtracting each incongruent trial from its most proximate congruent trial (but no further than five trials away) for each emotional facial expression type separately (Zvielli et al., 2015). The following TL-BS parameters were computed for painful and happy facial expressions, individually: Mean TL-BS Toward, the mean of all TL-BS scores $>0$ ms per person; Mean TL-BS AwAy, the mean of all TL-BS scores $<0$ ms per person; Peak TL-BS TowaRd, the maximum TL-BS or the peak AB toward target stimuli; Peak TL-BS away, the minimum TL-BS score or the peak AB away from target stimuli; and TL-BS Variability, an overall measure of the temporal stability of the AB towards and away from target stimuli over time, which is calculated by summing the distances between sequential TL-BS bias scores and dividing by the total number of TL-BS scores.

In line with best practice recommendations for $\mathrm{AB}$ research (Dear, Sharpe, Nicholas, \& Refshauge, 2011b; Price et al., 2015; Waechter, Nelson, Wright, Hyatt, \& Oakman, 2014), we calculated reliability estimates for traditional AB scores and TL-BS parameters. The Splithalf package (Parsons, 2018) was used to measure split-half reliability of the traditional AB scores, which allows bootstrapped split-half correlations performed for 5000 random splits, yielding more stable reliability estimates than the conventional method of odd-even splits of trials (Enock, Hofmann, \& McNally, 2014). The Spearman-Brown prophecy formula was used to correct for test length. The reliability of TL-BSs was measured by testing the association between each parameter from the first half of the task with its second half (Zvielli, Vrijsen, Koster, \& Bernstein, 2016).

\subsection{Data analysis}

Preliminary analyses included independent $t$-tests to examine the potential differences between groups on demographic and psychological variables. One sample $t$-tests were used to 
examine within-subject $\mathrm{AB}$ for each group separately. A series of two-way ANOVAs were performed with participant group (veterans or controls) as the between-group variable and type of target stimuli (painful or happy) as the within-group variable, with $\mathrm{AB}$ indices as dependent variables (i.e., AB, Mean TL-BS TOwARD, Mean TL-BS $_{\text {AwAy, Peak TL-BS }}$ TOwARD, Peak TL$\mathrm{BS}_{\mathrm{AWAY}}$, and TL-BS variability). Where significant effects were observed, $t$-tests were used to clarify differences. Additionally, $t$-tests were used to probe differences that were hypothesized a priori and approached significance. Partial eta-squared and Cohen's $d$ were applied to quantify effect sizes. The $\alpha$ was set to 0.05 for ANOVAs and $t$-tests. We also examined correlations between self-report measures and attentional indices using Pearson correlations and a Benjamini-Hochberg correction for controlling the false discovery rate (Benjamini \& Hochberg, 1995). The Benjamini-Hochberg method of controlling for multiple comparisons has been shown to be more powerful than comparable procedures that control the traditional familywise error rate (Benjamini \& Yekutieli, 2001). As an ancillary analysis designed to examine the role of PTSS more specifically and determine whether the significant effects were driven by PTSS or group status, we ran multiple regression analyses for the dependent variables that differed significantly between groups (see supplementary material).

\section{Results}

\subsection{Participant characteristics}

There were no significant differences between veterans and controls in terms of age, education, or fear of pain (Table 1). Veterans scored significantly higher on measures assessing symptoms of depression, anxiety, and stress compared to controls. On average, the veterans reported moderate-to-severe levels of depression, anxiety, and stress, while controls scored in the normal-to-mild range on these measures. Veterans also reported significantly more PTSS compared to controls (Veterans: $M=89.93, S D=19.9$; Controls: $M=59.9, S D=$ 12.48) 
Table 1

Comparison between characteristics of two groups

\begin{tabular}{lllcc}
\hline & Veterans & Controls & $t(d f)$ & p-value \\
\hline Age & $51.44(3.78)$ & $49.17(6.6)$ & $1.73(39.8)$ & 0.09 \\
Years of education & $12.06(3.84)$ & $13.33(3.62)$ & $1.49(82)$ & 0.14 \\
VAS-last week & $53.76(21.94)$ & - & - & - \\
VAS-current week & $42.15(24.62)$ & - & - & - \\
VAS-next week & $50.17(22.16)$ & - & - & - \\
Fear of pain & $79.09(16.78)$ & $72.3(19.54)$ & $1.67(82)$ & 0.098 \\
DASS - Depression & $19.83(10.45)$ & $5.73(5.06)$ & $8.3(80.8)$ & $<0.001$ \\
DASS - Anxiety & $20.11(8.06)$ & $5.8(4.89)$ & $10.11(81.3)$ & $<0.001$ \\
DASS - Stress & $27.63(8.37)$ & $13.93(8.27)$ & $7.21(82)$ & $<0.001$ \\
PTSD symptoms & $89.93(19.9)$ & $59.9(12.48)$ & $8.48(80.6)$ & $<0.001$ \\
\hline
\end{tabular}

\subsection{Traditional attentional bias Indices}

A 2 (groups: veterans, controls) $\times 2$ (type of stimuli: painful, happy) mixed-design ANOVA was conducted to determine whether veterans and controls differed in ABs for the target facial expressions. There was no main effect of group $\left[F(1,82)=3.144, p=0.08, \eta_{p}{ }^{2}\right.$ $=0.037]$ or type of stimuli $\left[F(1,82)=0.458, p=0.5, \eta_{p}{ }^{2}=0.006\right]$; however, the interaction effect for group and type of stimuli showed a trend towards significance $[F(1,82)=3.488, p$ $\left.=0.065, \eta_{p}{ }^{2}=0.041\right]$. Independent $t$-tests indicated that veterans and controls did not significantly differ $[t(82)=.277, p=.78]$ in their AB to happy facial expressions (Figure 1 ). There was a significant difference between groups for painful facial expressions $[t(82)=$ 2.59, $p=.011, d=0.57]$, where veterans displayed an AB away from the faces, while the opposite was true for controls.

One sample $t$-tests were used for each group separately to examine within-group ABs. $\mathrm{AB}$ index scores were compared to 0 as this would be indicative of no bias either towards or away from the target stimuli. The only significant finding was in the veteran group, who 
showed a significant $\mathrm{AB}$ away from painful facial expressions, $t(53)=3.65, p=.001, d=$ 0.49 .

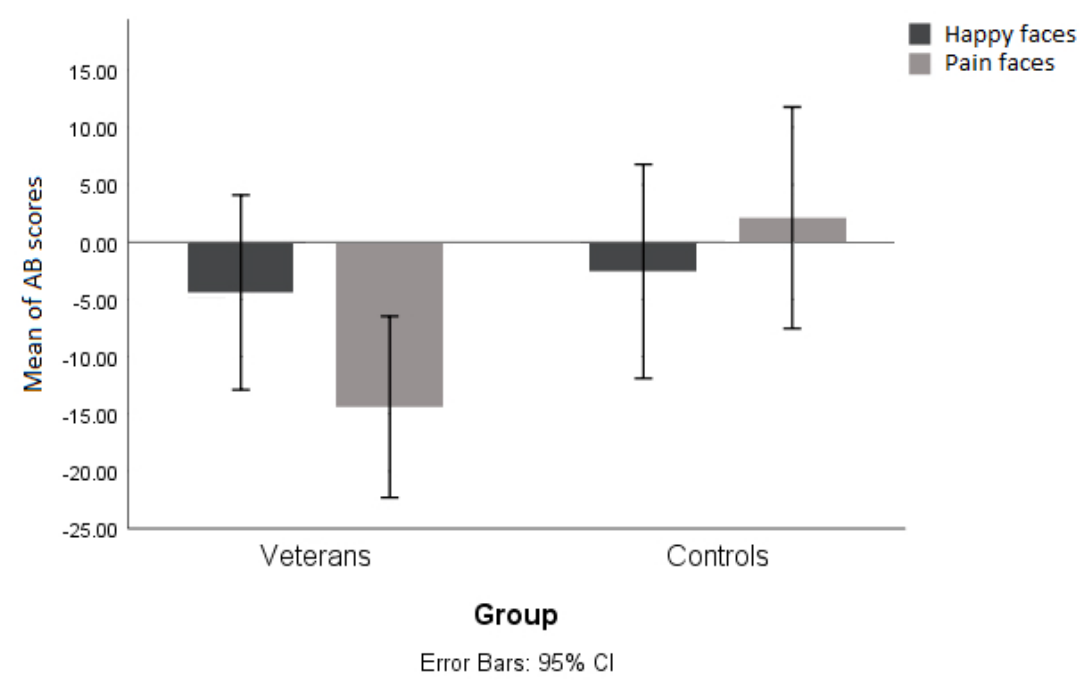

Fig. 1. Attentional biases for happy and painful facial expressions for veterans and controls (error bars represent $95 \%$ confidence interval)

\subsection{TL-BS parameters}

The mean number of paired trials for happy and painful facial expressions were 13.95 $(S D=1.87$, range: $10-18)$ and $13.3(S D=1.83$, range: $9-17)$, respectively. There was no significant difference between groups for the number of paired trials for happy $[t(82)=0.90$, $p=.37]$ or painful facial expressions $[t(82)=0.36, p=.71]$. Due to the high correlation between Mean and Peak TL-BS scores ( $r=.88$ to .93 ), only Mean TL-BS ${ }_{\text {TOward, }}$ Mean TL$\mathrm{BS}_{\mathrm{AWAY}}$, and TL-BS variability are reported to simplify the results. The patterns of results for Peak TL-BS TOWARD $_{\text {and Peak TL-BS }}$ AWAY were identical to Mean TL-BS TOWARD $_{\text {and }}$ Mean

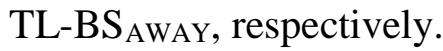

Table 2 presents the main effects of a series of three 2 (groups: veterans, controls) $\times 2$ (type of stimuli: painful, happy) mixed-design ANOVAs for each TL-BS parameter. As expected, veterans had significantly higher scores for all TL-BS parameters compared to control participants. No significant group by stimuli type interaction was found [all $F \mathrm{~s}(1,82)$ $\left.=0.013-0.350, p \mathrm{~s}>0.55, \eta_{p}^{2} \leq 0.004\right]$. 
Table 2

Descriptive statistics by Stimuli Types and main Effects for Group on TL-BS indices

\begin{tabular}{|c|c|c|c|c|c|c|c|}
\hline $\begin{array}{l}\text { TL-BS } \\
\text { indices } \\
\text { Stimuli } \\
\text { (Faces) }\end{array}$ & $\begin{array}{l}\text { Veterans (n } \\
=54) \\
M(S D)\end{array}$ & $\begin{array}{l}\text { Controls (n } \\
=30) \\
M(S D)\end{array}$ & $F_{(1,82)}$ & $p$ & $\eta_{p}^{2}$ & $M_{\text {diff }}$ & $95 \% \mathrm{CI}$ \\
\hline $\begin{array}{l}\text { Mean TL- } \\
\text { BS } S_{\text {TOWARD }}\end{array}$ & & & 10.77 & .002 & .116 & 36.96 & $\begin{array}{l}{[19.17,} \\
54.74]\end{array}$ \\
\hline Pain & $\begin{array}{l}108.01 \\
(81.45)\end{array}$ & $\begin{array}{c}66.86 \\
(24.10)\end{array}$ & & & & & \\
\hline Happy & $\begin{array}{l}102.51 \\
(57.03)\end{array}$ & $\begin{array}{c}69.80 \\
(28.57)\end{array}$ & & & & & \\
\hline $\begin{array}{l}\text { Mean TL- } \\
\text { BS }_{\text {AWAY }}\end{array}$ & & & 10.19 & .002 & .111 & -33.89 & $\begin{array}{c}{[-150.90,-} \\
16.87]\end{array}$ \\
\hline Pain & $\begin{array}{l}-104.31 \\
(66.73)\end{array}$ & $\begin{array}{l}-69.89 \\
(24.70)\end{array}$ & & & & & \\
\hline Happy & $\begin{array}{l}-102.43 \\
(53.48)\end{array}$ & $\begin{array}{l}-69.07 \\
(27.48)\end{array}$ & & & & & \\
\hline $\begin{array}{l}\text { TL-BS } \\
\text { Variability }\end{array}$ & & & 11.38 & .001 & .122 & 45.69 & $\begin{array}{l}{[24.51,} \\
66.87]\end{array}$ \\
\hline Pain & $\begin{array}{l}139.29 \\
(87.77)\end{array}$ & $\begin{array}{c}92.31 \\
(27.77)\end{array}$ & & & & & \\
\hline Happy & $\begin{array}{l}133.93 \\
(73.17)\end{array}$ & $\begin{array}{c}89.52 \\
(28.91)\end{array}$ & & & & & \\
\hline
\end{tabular}

\subsection{Controlling for general RT variability}

To rule out the alternative explanation that the observed results for TL-BSs are due to general RT variability, we calculated mean and SD of RT for neutral trials using the 16 practice trials as our experimental block did not include neutral trials. This approach has been used in past research (Zvielli et al., 2016). Group status remained significantly associated with TL-BS parameters above and beyond mean RT on neutral trials $\left[F(1,81)=5.39-6.39, p \leq .023, \eta_{p}{ }^{2}=\right.$ $.062-.073]$ as well as above and beyond the $S D$ of $\mathrm{RT}$ on neutral trials $[F(1,81)=6.66-7.78$, $\left.p \leq .012, \eta_{p}^{2}=.076-.088\right]$.

\subsection{Split-half reliability of attentional measures}

Split-half reliability measures for both groups and facial expression types are reported in Table 3. For all participants, TL-BS parameters showed higher reliabilities ( 0.27 to 0.74$)$ than traditional bias scores $(-33$ to -36$)$. 
Table 3

Split-Half reliability for Traditional Attentional Bias scores and TL-BS Parameters

\begin{tabular}{lcccccc}
\hline & $\begin{array}{c}\text { Traditional } \\
\text { AB }\end{array}$ & $\begin{array}{c}\text { Mean } \\
\text { TL-BS } \\
\text { TOwARD }\end{array}$ & $\begin{array}{c}\text { Mean } \\
\text { TL-BS } \\
\text { AwAY }\end{array}$ & $\begin{array}{c}\text { Peak } \\
\text { TL-BS } \\
\text { TOwARD }\end{array}$ & $\begin{array}{c}\text { Peak } \\
\text { TL-BS } \\
\text { AwAY }\end{array}$ & $\begin{array}{c}\text { TL-BS } \\
\text { Variability }\end{array}$ \\
\hline Pain & & & & & & \\
All $(\mathrm{n}=84)$ & -.36 & .52 & .44 & .50 & .43 & .74 \\
Veterans $(\mathrm{n}=54)$ & -.77 & .51 & .42 & .45 & .41 & .74 \\
Controls $(\mathrm{n}=30)$ & .26 & .32 & .24 & .59 & .27 & .40 \\
Happy & & & & & & \\
All $(\mathrm{n}=84)$ & -.33 & .31 & .27 & .40 & .43 & .44 \\
Veterans $(\mathrm{n}=54)$ & -.50 & .26 & .21 & .39 & .43 & .44 \\
Controls $(\mathrm{n}=30)$ & .16 & .14 & .33 & .14 & .09 & .03 \\
\hline
\end{tabular}

Note: Zvielli et al. (2015) advised 80 trials per emotional type for a meaningful calculation of TLBS reliability.

\subsection{Correlation analyses}

Correlational analyses for self-report measures and attentional indices were performed for all participants and each group separately using a Benjamini-Hochberg correction. Detailed results of these analyses are provided as supplementary material; here, we provide only a summary. Among all participants, TL-BS parameters from trials with happy facial expressions were significantly correlated with PTSS and symptoms of depression, anxiety, and stress. For trials with painful facial expressions, TL-BS parameters were significantly correlated with PTSS and TL-BS variability was significantly correlated with depression and stress. Among veterans, TL-BS parameters for happy facial expressions were significantly correlated with PTSS and symptoms of depression. The mentioned significant correlations suggest that greater temporal variability in $\mathrm{AB}$ is associated with more severe psychological symptoms. No significant correlations were observed for the control group.

\section{Discussion}

The current investigation examined $\mathrm{ABs}$ in individuals with co-occurring chronic pain and PTSS. The analytic approach involved the traditional measure of $\mathrm{AB}$, which serve to 
quantify the allocation of attention towards or away from emotional and non-emotional stimuli. The analytic approach also involved TL-BS parameters, variability-based measures that quantify the temporal dynamics of $\mathrm{AB}$. In what follows, the results relevant to each measure of $\mathrm{AB}$ and the associated implications will be discussed in turn.

With respect to the traditional $\mathrm{AB}$ scores, consistent with our hypotheses, neither veterans nor controls displayed an $\mathrm{AB}$ for happy facial expressions; however, veterans displayed an $\mathrm{AB}$ for painful facial expressions that was characterized by avoidance. The observed pattern of $\mathrm{AB}$ away from painful faces among veteran group was found both compared to controls (between-subject effect) and compared to neutral faces (within-subject effect). Caution is required with the interpretation of the between-subject effect as it was marginally significant. The within-subject effect indicates that veterans displayed a clear avoidance from painful faces compared to neutral faces, an effect that was not found among controls (Bar-Haim et al., 2007).

The avoidance of pain-related stimuli observed in the current investigation is somewhat inconsistent with the literature on $\mathrm{ABs}$ in individuals with chronic pain. Past research examining $\mathrm{ABs}$ in individuals with chronic pain has more commonly observed hypervigilance, or a bias towards pain-related stimuli (e.g., Haggman, Sharpe, Nicholas, \& Refshauge, 2010; Liossi, Schoth, Bradley, \& Mogg, 2009). One important difference between our investigation and those that observed hypervigilance for pain-related stimuli is that our participants with chronic pain were veterans with long-term injuries who also had PTSS. It is possible that the PTSS contributed to the observed change in direction of the AB, particularly given the critical connection between chronic pain and PTSS in the current sample. Since the majority of the veterans attributed their chronic pain to an injury sustained during a traumatic experience, traumatic memories would have a component of pain and experiences of pain could remind the veterans of their traumatic injuries (Liedl et al., 2010). For these 
individuals, avoiding pain (and reminders of trauma) may be doubly rewarding as it decreases pain and prevents recollections of the traumatic event that accompanied the pain (Fleurkens, Rinck, \& van Minnen, 2014). Nonetheless, this is largely speculation as the lack of PTSSonly and chronic pain-only groups for comparison in the current investigation make it impossible to draw conclusions regarding the influence of PTSS on the AB for pain-related stimuli.

A second possible explanation for the observed avoidance of pain-related stimuli in the veteran group relates to the circumstances surrounding their participation. The veterans performed the dot-probe task while they were waiting for a medical visit that required them to describe their traumatic injuries and associated health concerns in order to obtain financial compensation. This is typically a very stressful experience, and past research suggests that stress influences $\mathrm{AB}$. Although anxiety disorders are most often associated with hypervigilance for threat-related stimuli (Bar-Haim et al., 2007), the direction of the bias changes from hypervigilance to avoidance in stressful situations (Bar-Haim et al., 2010; Wald et al., 2013). This suppression of $A B$ in anxious individuals has been demonstrated in response to a range of stressful situations; studies have involved eminent stressors, such as telling veterans they will have to watch a combat video after the attention task (Constans, McCloskey, Vasterling, Brailey, \& Mathews, 2004) and intensive stressors such as real lifethreatening danger and combat exposure during war (Bar-Haim et al., 2010; Wald et al., 2011). Suppression of AB has been replicated in a series of studies on ABs and PTSD proposing that those who avoided threatening stimuli under stressful conditions displayed more symptoms and were at greater risk of developing PTSD (Sipos, Bar-Haim, Abend, Adler, \& Bliese, 2014; Wald et al., 2011). Given that the veterans who participated in our investigation were tested while they were waiting for a very important medical visit, it is unsurprising that they reported significantly more stress than the control group. This stress 
may have led to the pattern of avoidance we observed, instead of the hypervigilance often found in past research.

With respect to the temporal dynamics of $\mathrm{AB}$, veterans displayed greater TL-BSTOWARD, TL-BS AWAY, and TL-BS variability for both painful and happy facial expressions compared to controls. We observed significant correlations between TL-BS parameters and PTSS, depression, anxiety, and stress, indicating that greater temporal dynamics in $\mathrm{AB}$ are associated with more severe psychological symptoms. With regard to pain, no significant correlation was observed between pain-related measures and traditional attention bias measures or TL-BS parameters across all participants or each group separately. The lack of association between measures of $\mathrm{AB}$ and pain is consistent with past meta-analytic work showing no association between $\mathrm{AB}$ and pain-related individual difference variables, including pain severity and fear of pain (Crombez et al., 2013). However, replication is needed regarding the specific association between variability-based measures of $\mathrm{AB}$ and individual differences in pain as this study was the first to examine the relationship between the two.

Our results for TL-BS parameters support previous research that showed greater ABV for emotional stimuli in individuals with elevated PTSS, positive correlations between ABV and PTSS (Yuval et al., 2016; Naim et al., 2015), and positive correlations between measures of ABV and depression, anxiety and stress (Iacoviello et al., 2014; Swick \& Ashley, 2017; Zvielli et al., 2016). The results of the current investigation also support previous research that directly compared variability-based dot probe measures across positively and negatively valenced emotional stimuli and found that stimulus valence did not influence $A B$ temporal dynamics (Carlson, Aday, \& Rubin, 2018; Naim et al., 2015; Schäfer et al., 2016; Zvielli et al., 2016). Moreover, other studies have shown that positively-salient images can disrupt attention in anxious (Chen, Clarke, Watson, MacLeod, \& Guastella, 2014; Taylor, Bomyea, \& Amir, 2010) and traumatized populations (Blair et al., 2013; Fani et al., 2019). 
Findings from previous studies that have shown that elevated temporal dynamics of $A B$ are associated with higher levels of PTSS are consistent with the possibility that elevated TLBSs are a marker for PTSS. Identifying markers of psychopathology has theoretical and practical implications (Grant et al., 2003); however, the potential contributions of increased temporal variability in $\mathrm{AB}$ as a marker for PTSS are limited by the current state of the literature. The theoretical aspects of the association between variability in AB and PTSS have not been systematically examined. Clearly articulated and theory-driven models that explain the mechanisms by which greater variability in AB is associated with PTSS are needed to advance research in the field. One potential mechanism that may underlie differences in the temporal dynamics of $\mathrm{AB}$ is impaired top-down control processes (e.g., attentional control; (BaduraBrack et al., 2015; Swick \& Ashley, 2017). As such, impaired top-down control processes serve as a potential target for interventions designed to reduce PTSS. Attentional control training is an approach to attention modification that is believed to exert effects upon temporal dynamics of $\mathrm{AB}$ by enhancing attentional control (Badura-Brack et al., 2015). This training method, which is similar to control conditions in most attention bias modification studies, was more effective at decreasing PTSS compared to the usual look-away threat ABM (Badura-Brack et al., 2015) and bias-contingent ABM (Lazarov et al., 2018). Attentional control training does not train attention in a specific direction (i.e., towards or away from threat) but instead implicitly encourages participants to ignore the spatial locations of threatening stimuli to perform optimally on the task. Enhanced symptom reduction in attentional control training over $\mathrm{ABM}$ is thought to be due to improved attentional control (Basanovic, Notebaert, Grafton, Hirsch, \& Clarke, 2017). The above-mentioned studies did not directly assess attentional control (or other top-down control processes), precluding conclusive determinations of the mechanisms driving the enhanced effects of attentional control training. Further research specifically designed to elucidate the mechanisms underlying associations between 
psychopathology and the temporal dynamics of $\mathrm{AB}$ is needed to optimize the therapeutic benefits of attentional interventions.

We calculated the reliability scores for all attentional indices and found them to be low in most cases ${ }^{1}$. A few points should be noted when considering the reliability of $\mathrm{AB}$ assessment tasks. Low reliability inserts a serious issue for classifying individuals, as very high levels of assessment reliability is needed to classify individuals adequately, however, at the cohort level, patterns can be revealed effectively by instruments with lower levels of psychometric reliability (De Schryver, Hughes, Rosseel, \& De Houwer, 2016; MacLeod, Grafton, \& Notebaert, 2019; McNally, 2018; van Rooijen, Ploeger, \& Kret, 2017). This is considered to be the reason for the relative robustness of the significant differences in $\mathrm{AB}$ to threat between cohorts high and low in anxiety vulnerability (Armstrong \& Olatunji, 2012; Bar-Haim et al., 2007; Dudeney, Sharpe, \& Hunt, 2015). However, the above-mentioned point does not compromise the importance of increasing the reliability of $\mathrm{AB}$ assessment which should be a priority for future research.

We also calculated the reliability of TL-BS parameters which showed overall higher reliabilities compared to the traditional $\mathrm{AB}$ indices. However, the TL-BS reliabilities in our study were lower compared to previous studies (Schäfer et al., 2016; Zvielli et al., 2016). One contributor to the lower reliability of the TL-BS parameters in the present study is likely to be the smaller number of trials of our dot-probe task (Zvielli et al., 2015).

${ }^{1}$ We performed 5000 random splits for calculating the reliability of traditional $\mathrm{AB}$ scores, while previous studies mainly used other methods like odd-even splits. When we used odd-even method, the reliability scores that are obtained are higher than the more robust method of 5000 random split, for example -0.33 and -0.36 becomes 0.10 and -0.06 respectively which are closer to previous studies but still low. 
The findings of the current investigation must be considered in light of important limitations. First, the participants with chronic pain and PTSS were all men with combat-related index traumas, which limits the generalizability of the results. Second, the veteran and control groups were evaluated in different settings, which may have contributed to some of the observed differences. Third, the investigation would have benefited from the addition of threatrelated stimuli (e.g., combat-related) and the inclusion of PTSD-only and/or chronic-pain only groups for comparison. These additions would have allowed us to evaluate the specificity of the $\mathrm{AB}$ for pain-related stimuli compared to other negative stimuli, informed conclusions about the role of PTSS in the AB for pain-related stimuli, and provided more information about the role of pain as a reminder of trauma. Fourth, both happy and painful facial expressions were presented in the same block of trials and the number of trials per facial expression type was limited. Fifth, the M-PTSD was developed based on the DSM-III diagnostic criteria for PTSD, which differs from the current $D S M-5$ diagnostic criteria. Unfortunately, no study had tried to validate another PTSD measure in Iran and the existing study using by Goodarzi (2003) failed to report a cut-off point for the Persian version. The reported cut-off point of 107 for the English version appears to be much less sensitive and inefficient for categorizing in Iranian samples. Sixth, similar to many previous studies (Iacoviello et al., 2014; Swick \& Ashley, 2017), depression scores were correlated with $\mathrm{AB}$ scores that raise the question about the specificity of findings. Addressing this limitation has been a challenge for many studies in the literature as depression is highly comorbid with chronic pain and PTSD (Bair, Robinson, Katon, \& Kroenke, 2003; Stander, Thomsen, \& Highfill-McRoy, 2014).

Future research may address these limitations in a number of ways. First, including females and individuals with other types of traumas would improve the generalizability of these results. Second, assessing all participants in the same setting would increase confidence that observed differences are attributable to the variables of interest. Third, a greater number 
of trials and presenting different stimuli types in separate blocks would help a more effective reliability calculation and prevent possible carry-over effects of emotional stimuli respectively. Addition of neutral-neutral trials for buffering between experimental trials has been suggested as well (Zvielli et al., 2016). Fourth, future research could include clinicianadministered measures of PTSD. Other future directions include assessing attentional control as a potential moderating variable (Mazidi et al., in press), examining the time course of the $\mathrm{AB}$ for pain-related stimuli, and including threat-related stimuli in addition to pain-related stimuli and trials with two neutral stimuli in order to calculate attentional engagement and disengagement indices (Koster, Crombez, Verschuere, \& De Houwer, 2004).

In summary, the current investigation provides evidence of attentional dysfunction among veterans with chronic pain and PTSS. According to traditional AB measures, chronic pain and PTSS were associated with an AB away from pain-related stimuli on the pictorial dot-probe task, a finding that included both between-subject and within-subject effects. Furthermore, the current investigation was the first to provide evidence of overall attentional dysfunction for emotional stimuli in individuals with chronic pain and PTSS using variability-based $\mathrm{AB}$ measures. The avoidance of painful facial expressions observed in the current study suggests that the suppression of $\mathrm{AB}$ in individuals with chronic pain and PTSS that occurs during stressful situations may generalize to pain-related stimuli.

\section{Acknowledgments}

Authors would like to thank Professor Colin MacLeod for his comments and help during revision process. We also thank Mr. Saeedreza Shehnepoor and Dr. Julian Basanovic for their help with calculating trial level bias scores and reliability of the dot-probe task.

\section{References:}


Algom, D., Chajut, E., \& Lev, S. (2004). A rational look at the emotional stroop phenomenon: a generic slowdown, not a stroop effect. Journal of Experimental Psychology. General, 133(3), 323-338. https://doi.org/10.1037/0096-3445.133.3.323

Antony, M., J. Bieling, P., J. Cox, B., W. Enns, M., \& Swinson, R. (1998). Psychometric properties of the 42-item and 21-item versions of the Depression Anxiety Stress Scales in clinical groups and a community sample. Psychological Assessment (Vol. 10). https://doi.org/10.1037/1040-3590.10.2.176

Armstrong, T., \& Olatunji, B. O. (2012). Eye tracking of attention in the affective disorders: A meta-analytic review and synthesis. Clinical Psychology Review, 32(8), 704-723. https://doi.org/http://dx.doi.org/10.1016/j.cpr.2012.09.004

Asmundson, G. J. G., Coons, M. J., Taylor, S., \& Katz, J. (2002). PTSD and the experience of pain: research and clinical implications of shared vulnerability and mutual maintenance models. Canadian Journal of Psychiatry. Revue Canadienne de Psychiatrie, 47(10), 930-937. https://doi.org/10.1177/070674370204701004

Asmundson, G. J. G., \& Katz, J. (2009). Understanding the co-occurrence of anxiety disorders and chronic pain: state-of-the-art. Depression and Anxiety, 26(10), 888-901. https://doi.org/10.1002/da.20600

Badura-Brack, A. S., Naim, R., Ryan, T. J., Levy, O., Abend, R., Khanna, M. M., .. BarHaim, Y. (2015). Effect of attention training on attention bias variability and PTSD symptoms: Randomized controlled trials in Israeli and U.S. Combat Veterans. American Journal of Psychiatry, 172(12), 1233-1241. https://doi.org/10.1176/appi.ajp.2015.14121578

Bair, M. J., Robinson, R. L., Katon, W., \& Kroenke, K. (2003). Depression and pain comorbidity: a literature review. Archives of Internal Medicine, 163(20), 2433-2445. https://doi.org/10.1001/archinte.163.20.2433

Bar-Haim, Y., Holoshitz, Y., Eldar, S., Frenkel, T. I., Muller, D., Charney, D. S., ... Wald, I. (2010). Life-threatening danger and suppression of attention bias to threat. The American Journal of Psychiatry, 167(6), 694-698. https://doi.org/10.1176/appi.ajp.2009.09070956

Bar-Haim, Y., Lamy, D., Pergamin, L., Bakermans-Kranenburg, M. J., \& van IJzendoorn, M. H. (2007). Threat-related attentional bias in anxious and nonanxious individuals: a metaanalytic study. Psychological Bulletin, 133(1), 1-24. https://doi.org/10.1037/00332909.133.1.1

Bardeen, J. R., Daniel, T. A., Hinnant, J. B., \& Orcutt, H. K. (2017). Emotion dysregulation and threat-related attention bias variability. Motivation and Emotion, 41(3), 402-409. https://doi.org/10.1007/s11031-017-9604-Z

Basanovic, J., Notebaert, L., Grafton, B., Hirsch, C. R., \& Clarke, P. J. F. (2017). Attentional control predicts change in bias in response to attentional bias modification. Behaviour Research and Therapy, 99(September), 47-56. https://doi.org/10.1016/j.brat.2017.09.002

Beck, A. T., \& Clark, D. A. (1997). An information processing model of anxiety: automatic and strategic processes. Behaviour Research and Therapy, 35(1), 49-58.

Beck, J. G., Freeman, J. B., Shipherd, J. C., Hamblen, J. L., \& Lackner, J. M. (2001). 
Specificity of Stroop interference in patients with pain and PTSD. Journal of Abnormal Psychology, 110(4), 536-543.

Benjamini, Y., \& Hochberg, Y. (1995). Controlling the False Discovery Rate: A Practical and Powerful Approach to Multiple Testing. Journal of the Royal Statistical Society. Series B (Methodological), 57(1), 289-300. Retrieved from http://www.jstor.org/stable/2346101

Benjamini, Y., \& Yekutieli, D. (2001). The Control of the False Discovery Rate in Multiple Testing under Dependency. The Annals of Statistics, 29(4), 1165-1188. Retrieved from http://www.jstor.org/stable/2674075

Blair, K. S., Vythilingam, M., Crowe, S. L., Mccaffrey, D. E., Ng, P., Wu, C. C., \& Scaramozza, M. (2013). Cognitive control of attention is differentially affected in trauma-exposed individuals with and without post-traumatic stress disorder, 85-95. https://doi.org/10.1017/S0033291712000840

Bryant, R. A., Nickerson, A., Creamer, M., O’Donnell, M., Forbes, D., Galatzer-Levy, I., ... Silove, D. (2015). Trajectory of post-traumatic stress following traumatic injury: 6-year follow-up. The British Journal of Psychiatry: The Journal of Mental Science, 206(5), 417-423. https://doi.org/10.1192/bjp.bp.114.145516

Buckley, T. C., Galovski, T., Blanchard, E. B., \& Hickling, E. J. (2003). Is the emotional Stroop paradigm sensitive to malingering? A between-groups study with professional actors and actual trauma survivors. Journal of Traumatic Stress, 16(1), 59-66. https://doi.org/10.1023/A:1022063412056

Carleton, N. R., Duranceau, S., McMillan, K. A., \& Asmundson, G. J. G. (2018). Trauma, Pain, and Psychological Distress: Attentional Bias and Autonomic Arousal in PTSD and Chronic Pain. Journal of Psychophysiology, 32(2), 75-84. https://doi.org/10.1027/0269$8803 / \mathrm{a} 000184$

Carlson, J. M., Aday, J. S., \& Rubin, D. (2018). Temporal dynamics in attention bias: effects of sex differences, task timing parameters, and stimulus valence. Cognition \& Emotion, 1-6. https://doi.org/10.1080/02699931.2018.1536648

Chen, N. T. M., Clarke, P. J. F., Watson, T. L., MacLeod, C., \& Guastella, A. J. (2014). Biased Saccadic Responses to Emotional Stimuli in Anxiety: An Antisaccade Study. PLOS ONE, 9(2), e86474.

Cisler, J. M., \& Koster, E. H. W. (2010). Mechanisms of Attentional Biases towards Threat in the Anxiety Disorders: An Integrative Review. Clinical Psychology Review, 30(2), 203. https://doi.org/10.1016/j.cpr.2009.11.003

Classification of chronic pain. Descriptions of chronic pain syndromes and definitions of pain terms. Prepared by the International Association for the Study of Pain, Subcommittee on Taxonomy. (1986). Pain. Supplement, 3, S1-226.

Constans, J. I. (2005). Information processing biases in PTSD. In J. J. Vasterling \& C. R. Brewin (Eds.), Neuropsychology of PTSD: Biological, cognitive, and clinical perspectives (pp. 105-130). New York: Guilford Press.

Constans, J. I., McCloskey, M. S., Vasterling, J. J., Brailey, K., \& Mathews, A. (2004). Suppression of attentional bias in PTSD. Journal of Abnormal Psychology, 113(2), 315323. https://doi.org/10.1037/0021-843X.113.2.315 
Crombez, G., Eccleston, C., Van Damme, S., Vlaeyen, J. W. S., \& Karoly, P. (2012). Fearavoidance model of chronic pain: the next generation. The Clinical Journal of Pain, 28(6), 475-483. https://doi.org/10.1097/AJP.0b013e3182385392

Crombez, G., Van Ryckeghem, D. M. L., Eccleston, C., \& Van Damme, S. (2013). Attentional bias to pain-related information: a meta-analysis. Pain, 154(4), 497-510. https://doi.org/10.1016/j.pain.2012.11.013

De Schryver, M., Hughes, S., Rosseel, Y., \& De Houwer, J. (2016). Unreliable Yet Still Replicable: A Comment on LeBel and Paunonen (2011). Frontiers in Psychology, 6, 2039. https://doi.org/10.3389/fpsyg.2015.02039

Dear, B. F., Sharpe, L., Nicholas, M. K., \& Refshauge, K. (2011a). Pain-related attentional biases: the importance of the personal relevance and ecological validity of stimuli. The Journal of Pain: Official Journal of the American Pain Society, 12(6), 625-632. https://doi.org/10.1016/j.jpain.2010.11.010

Dear, B. F., Sharpe, L., Nicholas, M. K., \& Refshauge, K. (2011b). The Psychometric Properties of the Dot-Probe Paradigm When Used in Pain-Related Attentional Bias Research. The Journal of Pain, 12(12), 1247-1254. https://doi.org/http://dx.doi.org/10.1016/j.jpain.2011.07.003

Dehghani, M., Mohammadi, S., Sharpe, L., \& Khatibi, A. (2018). Attentional Bias to ThreatRelated Information Among Individuals With Dental Complaints: The Role of Pain Expectancy. Frontiers in Psychology, 9, 786. https://doi.org/10.3389/fpsyg.2018.00786

Dehghani, M., Sharpe, L., \& Nicholas, M. K. (2004). Modification of attentional biases in chronic pain patients: a preliminary study. European Journal of Pain, 8(6), 585-594. https://doi.org/http://dx.doi.org/10.1016/j.ejpain.2004.02.003

Dudeney, J., Sharpe, L., \& Hunt, C. (2015). Attentional bias towards threatening stimuli in children with anxiety: A meta-analysis. Clinical Psychology Review, 40, 66-75. https://doi.org/10.1016/j.cpr.2015.05.007

Elsesser, K., Sartory, G., \& Tackenberg, A. (2004). Attention, heart rate, and startle response during exposure to trauma-relevant pictures: a comparison of recent trauma victims and patients with posttraumatic stress disorder. Journal of Abnormal Psychology, 113(2), 289-301. https://doi.org/10.1037/0021-843X.113.2.289

Elsesser, K., Sartory, G., \& Tackenberg, A. (2005). Initial symptoms and reactions to traumarelated stimuli and the development of posttraumatic stress disorder. Depression and Anxiety, 21(2), 61-70. https://doi.org/10.1002/da.20047

Enock, P. M., Hofmann, S. G., \& McNally, R. J. (2014). Attention Bias Modification Training Via Smartphone to Reduce Social Anxiety: A Randomized, Controlled MultiSession Experiment. Cognitive Therapy and Research, 38(2), 200-216. https://doi.org/10.1007/s10608-014-9606-z

Erceg-Hurn, D. M., \& Mirosevich, V. M. (2008). Modern robust statistical methods: an easy way to maximize the accuracy and power of your research. The American Psychologist, 63(7), 591-601. https://doi.org/10.1037/0003-066X.63.7.591

Fani, N., Bradley-Davino, B., Ressler, K. J., \& McClure-Tone, E. B. (2011). Attention Bias in Adult Survivors of Childhood Maltreatment with and without Posttraumatic Stress Disorder. Cognitive Therapy and Research, 35(1), 57-67. 
https://doi.org/10.1007/s10608-010-9294-2

Fani, N., King, T. Z., Clendinen, C., Hardy, R. A., Surapaneni, S., Blair, J. R., ... Bradley, B. (2019). Attentional control abnormalities in posttraumatic stress disorder: Functional, behavioral, and structural correlates. Journal of Affective Disorders, 253, 343-351. https://doi.org/10.1016/j.jad.2019.04.098

Fani, N., Tone, E. B., Phifer, J., Norrholm, S. D., Bradley, B., Ressler, K. J., ... Jovanovic, T. (2012). Attention bias toward threat is associated with exaggerated fear expression and impaired extinction in PTSD. Psychological Medicine, 42(3), 533-543. https://doi.org/10.1017/S0033291711001565

Ferraz, M. B., Quaresma, M. R., Aquino, L. R., Atra, E., Tugwell, P., \& Goldsmith, C. H. (1990). Reliability of pain scales in the assessment of literate and illiterate patients with rheumatoid arthritis. The Journal of Rheumatology, 17(8), 1022-1024.

Fishbain, D. A., Pulikal, A., Lewis, J. E., \& Gao, J. (2017). Chronic Pain Types Differ in Their Reported Prevalence of Post -Traumatic Stress Disorder (PTSD) and There Is Consistent Evidence That Chronic Pain Is Associated with PTSD: An Evidence-Based Structured Systematic Review. Pain Medicine (Malden, Mass.), 18(4), 711-735. https://doi.org/10.1093/pm/pnw065

Fleurkens, P., Rinck, M., \& van Minnen, A. (2014). Implicit and explicit avoidance in sexual trauma victims suffering from posttraumatic stress disorder: a pilot study. European Journal of Psychotraumatology, 5, 10.3402/ejpt.v5.21359. https://doi.org/10.3402/ejpt.v5.21359

Goodarzi, M. (2003). Reliability and validity of Mississippi Post-Traumatic Stress Disorder (PTSD) scale. Journal of Psychology, 7(2), 153-178.

Grant, K. E., Compas, B. E., Stuhlmacher, A. F., Thurm, A. E., Mcmahon, S. D., Halpert, J. A., \& Al, G. E. T. (2003). Stressors and Child and Adolescent Psychopathology: Moving From Markers to Mechanisms of Risk. Psychological Bulletin, 129(3), 447466. https://doi.org/10.1037/0033-2909.129.3.447

Haggman, S. P., Sharpe, L. A., Nicholas, M. K., \& Refshauge, K. M. (2010). Attentional Biases Toward Sensory Pain Words in Acute and Chronic Pain Patients. The Journal of Pain, 11(11), 1136-1145. https://doi.org/http://dx.doi.org/10.1016/j.jpain.2010.02.017

Hawker, G. A., Mian, S., Kendzerska, T., \& French, M. (2011). Measures of adult pain: Visual Analog Scale for Pain (VAS Pain), Numeric Rating Scale for Pain (NRS Pain), McGill Pain Questionnaire (MPQ), Short-Form McGill Pain Questionnaire (SF-MPQ), Chronic Pain Grade Scale (CPGS), Short Form-36 Bodily Pain Scale (SF. Arthritis Care \& Research, 63 Suppl 1, S240-52. https://doi.org/10.1002/acr.20543

Iacoviello, B. M., Wu, G., Abend, R., Murrough, J. W., Feder, A., Fruchter, E., ... Charney, D. S. (2014). Attention bias variability and symptoms of posttraumatic stress disorder. Journal of Traumatic Stress, 27(2), 232-239. https://doi.org/10.1002/jts.21899

Keane, T. M., Caddell, J. M., \& Taylor, K. L. (1988). Mississippi Scale for Combat-Related Posttraumatic Stress Disorder: three studies in reliability and validity. Journal of Consulting and Clinical Psychology, 56(1), 85-90.

Khatibi, A., Dehghani, M., Sharpe, L., Asmundson, G. J. G., \& Pouretemad, H. (2009). Selective attention towards painful faces among chronic pain patients: Evidence from a 
modified version of the dot-probe. Pain, 142(1-2), 42-47.

https://doi.org/10.1016/j.pain.2008.11.020

Kimble, M. O., Frueh, B. C., \& Marks, L. (2009). Does the modified Stroop effect exist in PTSD? Evidence from dissertation abstracts and the peer reviewed literature. Journal of Anxiety Disorders, 23(5), 650-655. https://doi.org/http://dx.doi.org/10.1016/j.janxdis.2009.02.002

Koster, E. H. W., Crombez, G., Verschuere, B., \& De Houwer, J. (2004). Selective attention to threat in the dot probe paradigm: differentiating vigilance and difficulty to disengage. Behaviour Research and Therapy, 42(10), 1183-1192. https://doi.org/10.1016/j.brat.2003.08.001

Kulka, R., Schlenger, W., Fairbanks, J., Hough, R., Jordan, K., Marmar, C., ... Grady, D. (1990). Trauma and the Vietnam War generation: report on the findings from the national vietnam veterans readjustment study. New York: Brunner/Mazel.

Lazarov, A., Suarez-jimenez, B., Abend, R., Naim, R., Shvil, E., Helpman, L., ... Neria, Y. (2018). Bias-contingent attention bias modification and attention control training in treatment of PTSD : a randomized control trial.

Leeuw, M., Goossens, M. E. J. B., Linton, S. J., Crombez, G., Boersma, K., \& Vlaeyen, J. W. S. (2007). The fear-avoidance model of musculoskeletal pain: current state of scientific evidence. Journal of Behavioral Medicine, 30(1), 77-94. https://doi.org/10.1007/s10865-006-9085-0

Liedl, A., O’Donnell, M., Creamer, M., Silove, D., McFarlane, A., Knaevelsrud, C., \& Bryant, R. A. (2010). Support for the mutual maintenance of pain and post-traumatic stress disorder symptoms. Psychological Medicine, 40(7), 1215-1223. https://doi.org/10.1017/S0033291709991310

Liossi, C., Schoth, D. E., Bradley, B. P., \& Mogg, K. (2009). Time-course of attentional bias for pain-related cues in chronic daily headache sufferers. European Journal of Pain (London, England), 13(9), 963-969. https://doi.org/10.1016/j.ejpain.2008.11.007

Lovibond, P. F., \& Lovibond, S. H. (1995). The structure of negative emotional states: comparison of the Depression Anxiety Stress Scales (DASS) with the Beck Depression and Anxiety Inventories. Behaviour Research and Therapy, 33(3), 335-343.

MacLeod, C., Grafton, B., \& Notebaert, L. (2019). Anxiety-Linked Attentional Bias: Is It Reliable? Annual Review of Clinical Psychology. https://doi.org/10.1146/annurevclinpsy-050718-095505

MacLeod, C., Mathews, A., \& Tata, P. (1986). Attentional bias in emotional disorders. Journal of Abnormal Psychology, 95(1), 15-20.

Mahmoodi-Aghdam, M., Dehghani, M., Ahmadi, M., Khorrami Banaraki, A., \& Khatibi, A. (2017). Chronic Pain and Selective Attention to Pain Arousing Daily Activity Pictures: Evidence From an Eye Tracking Study. Basic and Clinical Neuroscience, 8(6), 467478. https://doi.org/10.29252/nirp.bcn.8.6.467

Mathews, A., \& Mackintosh, B. (1998). A Cognitive Model of Selective Processing in Anxiety. Cognitive Therapy and Research, 22(6), 539-560. https://doi.org/10.1023/A:1018738019346

Mazidi, M., Dehghani, M., Sharpe, L., Dolatshahi, B., Ranjbar, S., \& Khatibi, A. (In press). 
Time-course of attentional bias to painful facial expressions and the moderating role of attentional control: an eye-tracking study. British Journal of Pain.

McFall Miles, E., Smith Dale, E., Mackay Priscilla, W., \& Tarver David, J. (1990).

Reliability and validity of Mississippi Scale for Combat-Related Posttraumatic Stress Disorder. Psychological Assessment, 2(2), 114-121.

McNally, R. J. (2018). Attentional bias for threat: Crisis or opportunity? Clinical Psychology Review. https://doi.org/10.1016/j.cpr.2018.05.005

McNeil, D. W., \& Rainwater, A. J. 3rd. (1998). Development of the Fear of Pain Questionnaire--III. Journal of Behavioral Medicine, 21(4), 389-410.

Mohammadi, S., Dehghani, M., Khatibi, A., Sanderman, R., \& Hagedoorn, M. (2015). Caregivers' attentional bias to pain: does it affect caregiver accuracy in detecting patient pain behaviors? Pain, 156(1), 123-130. https://doi.org/10.1016/j.pain.0000000000000015

Naim, R., Abend, R., Wald, I., Eldar, S., Levi, O., Fruchter, E., ... Bar-Haim, Y. (2015). Threat-related attention bias variability and posttraumatic stress. American Journal of Psychiatry, 172(12), 1242-1250. https://doi.org/10.1176/appi.ajp.2015.14121579

Nusseck, M., Cunningham, D. W., Wallraven, C., \& Bulthoff, H. H. (2008). The contribution of different facial regions to the recognition of conversational expressions. Journal of Vision, 8(8), 1.1-23. https://doi.org/10.1167/8.8.1

Parsons, S. (2018). splithalf: robust estimates of split half reliability (Version 3). figshare. Retrieved from https://doi.org/10.6084/m9.figshare.5559175.v4

Price, R. B., Kuckertz, J. M., Siegle, G. J., Ladouceur, C. D., Silk, J. S., Ryan, N. D., ... Amir, N. (2015). Empirical recommendations for improving the stability of the dotprobe task in clinical research. Psychological Assessment, 27(2), 365-376. https://doi.org/10.1037/pas0000036

Ravn, S. L., Vaegter, H. B., Cardel, T., \& Andersen, T. E. (2018). The role of posttraumatic stress symptoms on chronic pain outcomes in chronic pain patients referred to rehabilitation. Journal of Pain Research, 11, 527-536. https://doi.org/10.2147/JPR.S155241

Roelofs, J., Peters, M. L., Fassaert, T., \& Vlaeyen, J. W. S. (2005). The role of fear of movement and injury in selective attentional processing in patients with chronic low back pain: A dot-probe evaluation. Journal of Pain, 6(5), 294-300. https://doi.org/10.1016/j.jpain.2004.12.011

Roy, S., Roy, C., Fortin, I., Ethier-Majcher, C., Belin, P., \& Gosselin, F. (2007). A dynamic facial expression database. Journal of Vision, 7(9), 944.

Schäfer, J., Bernstein, A., Zvielli, A., Höfler, M., Wittchen, H.-U., \& Schönfeld, S. (2016). Attentioan bias temporal dynamics predict post-traumatic stress symptoms: a prospective-longitudinal study among soldiers. Depression and Anxiety, 33(7), 630-639. https://doi.org/10.1002/da.22526

Schafer, J., Zvielli, A., Hofler, M., Wittchen, H.-U., \& Bernstein, A. (2018). Trauma, attentional dysregulation, and the development of posttraumatic stress: An investigation of risk pathways. Behaviour Research and Therapy, 102, 60-66.

https://doi.org/10.1016/j.brat.2018.01.004 
Sharp, T. J., \& Harvey, A. G. (2001). Chronic pain and posttraumatic stress disorder: mutual maintenance? Clinical Psychology Review, 21(6), 857-877. https://doi.org/http://dx.doi.org/10.1016/S0272-7358(00)00071-4

Sipos, M. L., Bar-Haim, Y., Abend, R., Adler, A. B., \& Bliese, P. D. (2014). Postdeployment threat-related attention bias interacts with combat exposure to account for PTSD and anxiety symptoms in soldiers. Depression and Anxiety, 31(2), 124-129. https://doi.org/10.1002/da.22157

Siqveland, J., Hussain, A., Lindstrom, J. C., Ruud, T., \& Hauff, E. (2017). Prevalence of Posttraumatic Stress Disorder in Persons with Chronic Pain: A Meta-analysis. Frontiers in Psychiatry, 8, 164. https://doi.org/10.3389/fpsyt.2017.00164

Spruyt, A., Clarysse, J., Vansteenwegen, D., Baeyens, F., \& Hermans, D. (2010). Affect 4.0: a free software package for implementing psychological and psychophysiological experiments. Experimental Psychology, 57(1), 36-45. https://doi.org/10.1027/16183169/a000005

Stander, V. A., Thomsen, C. J., \& Highfill-McRoy, R. M. (2014). Etiology of depression comorbidity in combat-related PTSD: A review of the literature. Clinical Psychology Review, 34(2), 87-98. https://doi.org/http://dx.doi.org/10.1016/j.cpr.2013.12.002

Stein, M. B., Walker, J. R., Hazen, A. L., \& Forde, D. R. (1997). Full and partial posttraumatic stress disorder: findings from a community survey. The American Journal of Psychiatry, 154(8), 1114-1119. https://doi.org/10.1176/ajp.154.8.1114

Stroop, J. R. (1935). Studies of interference in serial verbal reactions. Journal of Experimental Psychology, 18(6), 643-662. https://doi.org/http://dx.doi.org/10.1037/h0054651

Swick, D., \& Ashley, V. (2017). Enhanced Attentional Bias Variability in Post-Traumatic Stress Disorder and its Relationship to More General Impairments in Cognitive Control. Scientific Reports, 7(1), 14559. https://doi.org/10.1038/s41598-017-15226-7

Taylor, C. T., Bomyea, J., \& Amir, N. (2010). Attentional bias away from positive social information mediates the link between social anxiety and anxiety vulnerability to a social stressor. Journal of Anxiety Disorders, 24(4), 403-408. https://doi.org/10.1016/j.janxdis.2010.02.004

Thomas, C. L., Goegan, L. D., Newman, K. R., Arndt, J. E., \& Sears, C. R. (2013). Attention to threat images in individuals with clinical and subthreshold symptoms of posttraumatic stress disorder. Journal of Anxiety Disorders, 27(5), 447-455. https://doi.org/10.1016/j.janxdis.2013.05.005

van Rooijen, R., Ploeger, A., \& Kret, M. E. (2017). The dot-probe task to measure emotional attention: A suitable measure in comparative studies? Psychonomic Bulletin \& Review, 24(6), 1686-1717. https://doi.org/10.3758/s13423-016-1224-1

Waechter, S., Nelson, A. L., Wright, C., Hyatt, A., \& Oakman, J. (2014). Measuring attentional bias to threat: Reliability of dot probe and eye movement indices. Cognitive Therapy and Research, 38(3), 313-333. https://doi.org/10.1007/s10608-013-9588-2

Wald, I., Degnan, K. A., Gorodetsky, E., Charney, D. S., Fox, N. A., Fruchter, E., ... BarHaim, Y. (2013). Attention to threats and combat-related posttraumatic stress symptoms: prospective associations and moderation by the serotonin transporter gene. JAMA 
Psychiatry, 70(4), 401-408. https://doi.org/10.1001/2013.jamapsychiatry.188

Wald, I., Lubin, G., Holoshitz, Y., Muller, D., Fruchter, E., Pine, D. S., ... Bar-Haim, Y. (2011). Battlefield-like stress following simulated combat and suppression of attention bias to threat. Psychological Medicine, 41(4), 699-707. https://doi.org/10.1017/S0033291710002308

Wald, I., Shechner, T., Bitton, S., Holoshitz, Y., Charney, D. S., Muller, D., ... Bar-Haim, Y. (2011). Attention bias away from threat during life threatening danger predicts PTSD symptoms at one-year follow-up. Depression and Anxiety, 28(5), 406-411. https://doi.org/10.1002/da.20808

Wood, B. M., Nicholas, M. K., Blyth, F., Asghari, A., \& Gibson, S. (2010). Assessing pain in older people with persistent pain: the NRS is valid but only provides part of the picture. The Journal of Pain : Official Journal of the American Pain Society, 11(12), 1259-1266. https://doi.org/10.1016/j.jpain.2010.02.025

Yuval, K., Zvielli, A., \& Bernstein, A. (2016). Attentional Bias Dynamics and Posttraumatic Stress in Survivors of Violent Conflict and Atrocities: New Directions in Clinical Psychological Science of Refugee Mental Health. Clinical Psychological Science, 5(1), 64-73. https://doi.org/10.1177/2167702616649349

Zvielli, A., Bernstein, A., \& Koster, E. H. W. (2015). Temporal Dynamics of Attentional Bias. Clinical Psychological Science, 3(5), 772-788. https://doi.org/10.1177/2167702614551572

Zvielli, A., Vrijsen, J. N., Koster, E. H. W., \& Bernstein, A. (2016). Attentional bias temporal dynamics in remitted depression. Journal of Abnormal Psychology, 125(6), 768-776. https://doi.org/10.1037/abn0000190 


\section{Regression analyses}

To examine the role of PTSS more specifically, we ran multiple regression analyses for ANOVA significant effects to examine whether the effects were driven by PTSS or group status.

With respect to the significant difference between the veteran and control groups in $A B$ to painful facial expressions, multiple regression was used with $\mathrm{AB}$ to painful facial expressions as the outcome variable and PTSS and group status as predictor variables. The model significantly predicted $\mathrm{AB}$ to painful facial expressions $\left(R^{2} \mathrm{~s}=0.05, F(2,83)=3.37, p=\right.$ 0.039), but neither PTSS ( $\beta=-0.05, p=0.77)$, nor group status $(\beta=-14.95, p=0.075)$ uniquely predicted $\mathrm{AB}$ to painful facial expressions. This suggests that the difference could not be attributed uniquely to each PTSS or group status alone and is driven by the combination of both of these factors.

Concerning the significant between-subject effects of the mixed-design ANOVAs for each TL-BS parameter, a series of multiple linear regressions were calculated to predict TLBS parameters based on PTSS and group status. As the ANOVA did not show significant interaction effects, the mean scores for each TL-BS parameter were calculated from happy and painful facial expressions and were included as criterion variables. Results indicated that for TL-BS variability, TL-BS AWAY, and TL-BS TOWARD, the predictors explained $19 \%, 18 \%$ and $16 \%$ of the variance, respectively $\left(R^{2} \mathrm{~s}=0.19,0.18,0.16, F \mathrm{~s}(2,83)=10.7,10.4,8.64, p \mathrm{~s} \leq\right.$ 0.013). PTSS was the only significant predictor for TL-BS variability $(\beta=1.06, p=0.004)$, TL-BS TOWARD $(\beta=0.88, p=0.004)$, and TL-BS AWAY $(\beta=-0.72, p=0.013)$. Beta values (both positive and negative) indicate that increases in PTSS scores are associated with increases in the temporal dynamics of attentional bias. Therefore, the group differences in TL-BS parameters seem to be mainly driven by higher PTSS scores in the veteran group as the 
regression analyses showed that M-PTSD scores, not group status, predicted TL-BS parameters. 


\section{Table S1}

Pearson correlation coefficients between attentional measures with questionnaire measures for all participants $(n=84)$

\begin{tabular}{clccccc}
\hline & \multicolumn{1}{c}{ Attentional measures } & PTSD & FOP & Depression & Anxiety & Stress \\
\hline \multirow{2}{*}{ Pain } & Aggregated Mean Bias & -.200 & -.216 & -.215 & -.226 & -.191 \\
faces & TL-BS variability & $.370^{*}$ & .123 & $.296^{*}$ & .240 & $.304 *$ \\
& Mean TL-BS Toward & $.363^{*}$ & .052 & .293 & .256 & .276 \\
& Mean TL-BS Away & $-.311^{*}$ & -.196 & -.269 & -.224 & -.257 \\
Happy & Aggregated Mean Bias & & & & -.010 & .010 \\
faces & TL-BS variability & -.043 & .110 & .046 & $.343^{*}$ & $.337^{*}$ \\
& Mean TL-BS Toward & $.447 *$ & .176 & $.437 *$ & $.300^{*}$ & $.315^{*}$ \\
& Mean TL-BS Away & $.419 *$ & .116 & $.392^{*}$ & $-.341^{*}$ & $-.352^{*}$ \\
\hline
\end{tabular}

* Significant correlations

7 


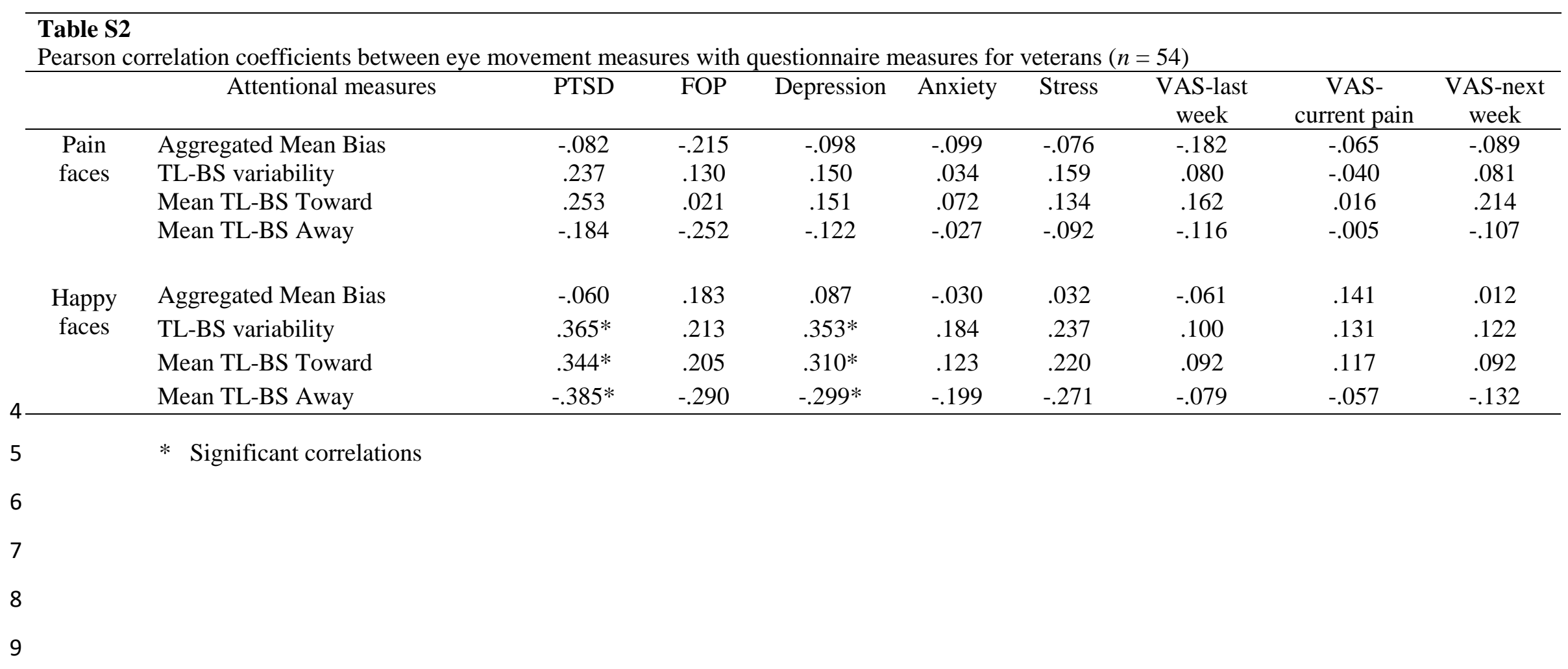




\begin{tabular}{llccccc}
\hline $\begin{array}{l}\text { Table S3 } \\
\text { Pearson correlation coefficients between eye movement measures with questionnaire measures for controls } \\
(n=30)\end{array}$ & \multicolumn{7}{c}{ A } \\
\hline \multicolumn{2}{c}{ Attentional measures } & PTSD & FOP & Depression & Anxiety & Stress \\
\hline Pain & Aggregated Mean Bias & .126 & -.110 & .078 & .119 & .078 \\
faces & TL-BS variability & .350 & -.157 & .167 & .153 & .231 \\
& Mean TL-BS Toward & .226 & -.108 & .238 & .209 & .195 \\
& Mean TL-BS Away & -.114 & .181 & -.158 & -.101 & -.210 \\
& & & & & & \\
Happy & Aggregated Mean Bias & .077 & -.004 & .067 & .190 & .049 \\
& TL-BS variability & .056 & -.165 & -.055 & .035 & -.042 \\
& Mean TL-BS Toward & .075 & -.362 & -.022 & .137 & -.004 \\
& Mean TL-BS Away & -.081 & .057 & .127 & .054 & .037 \\
\hline
\end{tabular}

No significant correlations were found for the control group 